East African Medical Journal Vol. 81 No. 5 May 2004

RETINITIS PIGMENTOSA IN BENIN, NIGERIA

C. U. Ukponmwan, MBBS, FMC, (Ophthal), FWACS, Senior Lecturer/Consultant Ophthalmologist, and A. Atamah, Registrar in Ophthalmology, University of Benin Teaching Hospital, P.O. Box 7139, Benin City, Edo State, Nigeria

Request for reprints to: Dr. C. U. Ukponmwan, University of Benin Teaching Hospital, P.O. Box 7139, Benin City, Edo State, Nigeria

\title{
RETINITIS PIGMENTOSA IN BENIN, NIGERIA
}

\author{
C. U. UKPONMWAN and A. ATAMAH
}

\begin{abstract}
Objectives: To determine the mode of presentation and degree of visual impairment of retinitis pigmentosa in Nigerians.

Design: A prospective, non-comparative study.

Setting: University of Benin Teaching Hospital, Benin City, Nigeria.

Subjects: Thirty Nigerian patients with a diagnosis of retinitis pigmentosa who presented at the Eye Clinic of the Ophthalmology Department of the University of Benin, Teaching Hospital, Benin City, Nigeria over a three year period (July 1997-June 2000) were included in the study. The clinical features and mode of presentation were noted. The examination included visual acuity, slit lamp examination and fundoscopy.

Main outcome measures: Presenting symptoms and signs, visual acuity.

Results: The degree of visual impairment and clinical features in thirty Nigerians with retinitis pigmentosa seen at the University of Benin Teaching Hospital, Benin City, Nigeria were studied. There were twenty males and ten females. The age range was 14 to 71 years (mean 36.7 years \pm 14.8 years). Fifteen patients $(50 \%)$ had visual acuity of less than $3 / 60$ while only seven $(23.3 \%)$ had visual acuity of $6 / 12$ or better.

The commonest mode of presentation was poor vision in $90 \%$ of the patients followed by night blindness in $56.7 \%$. Others were headaches, flashes of light and floaters. Conclusion: The degree of visual loss in Nigerians with retinitis pigmentosa is severe and may be related to the long duration of the disease and age of the patients at presentation. Health education of the public and patients about the need for early presentation to hospital and the use of vitamin $A$ and carbonic anhydrase inhibitors are recommended.
\end{abstract}

\section{INTRODUCTION}

Retinitis pigmentosa is a group of genetically heterogeneous diseases with autosomal recessive, autosomal dominant and $\mathrm{X}$-linked modes of inheritance $(1,2)$. It is characterised by degeneration of photoreceptors and pigment epithelium(3-5). Retinitis pigmentosa is defined by a spectrum of inherited progressive retinal degeneration characterised by night blindness, progressive visual field loss, reduced or non detectable electroretinogram amplitude, loss of visual acuity and characteristic pigmentary changes of the retina $(3,5,6)$.

There has been little or no report on the clinical features and degree of visual impairment of retinitis pigmentosa in Nigeria and this study was carried out in Benin City, Nigeria, to determine its mode of presentation and degree of visual loss in Nigerians.

\section{MATERIALS AND METHODS}

All consecutive patients with a clinical diagnosis of retinitis pigmentosa seen over a three year period (July 1997 to June 2000) at the University of Benin Teaching Hospital, Benin City were included in the study. The sex, age, occupation, family history of any ocular disease or visual loss were noted. The patients were asked about the presence of night blindness, headache, flashes of light, hearing defect and their responses were noted. All the patients were examined by the first author. The examination included visual acuity using the Snellen's chart, slip lamp examination, the presence or absence of lens opacities (cataract) and detailed retinal examination (fundoscopy). The best-corrected visual acuity was recorded. The best-corrected monocular visual acuity obtained from each patient was used in the analysis. Electoretinographic testing was not done in these patients due to the non-availability of the equipment in this centre and so the diagnosis of retinitis pigmentosa was made from the clinical findings. These findings were then analysed.

\section{RESULTS}

Thirty patients were seen with a diagnosis of retinitis pigmentosa during the study period. There were twenty males and ten females. The age range of the patients was 14 years to 71 years with a mean age of $36.7 \pm 14.8$ years. Table 1 shows the number of patients in each age group. The highest number of patients, fourteen $(46.7 \%)$ was seen in the age group 21-40 years. Only one patient was seen above 60 years of age. 
Table 2 shows the visual acuity of the patients. One patient presented with a vision of no light perception in both eyes. Fifteen patients $(50 \%)$ had visual acuity of less than $3 / 60$. Seven patients $(23.3 \%)$ had visual acuity of $6 / 12$ or better. Three patients had asymmetry of vision between both eyes with a difference of more than two lines on the Snellen's chart.

Table 1

Age range of patients with retinitis pigmentosa

\begin{tabular}{lll}
\hline Age range (years) & No. of patients & $(\%)$ \\
\hline$\leq 20$ & 4 & 13.3 \\
$21-40$ & 14 & 46.7 \\
$41-60$ & 11 & 36.7 \\
61 & 1 & 3.3 \\
\hline Total & 30 & 100 \\
\hline
\end{tabular}

Table 2

Visual acuity in patients with retinitis pigmentosa

\begin{tabular}{lcc}
\hline Visual acuity & No. of patients & $(\%)$ \\
\hline $6 / 5-6 / 12$ & 7 & 23.3 \\
$6 / 18->6 / 60$ & 8 & 26.7 \\
$6 / 60-3 / 60$ & - & - \\
$>3 / 60 \geq$ CF & 3 & 10 \\
CF-LP & 11 & 36.7 \\
NLP & 1 & 3.3 \\
\hline Total & 30 & 100 \\
\hline
\end{tabular}

$\mathrm{NB}: \mathrm{CF}=$ Count fingers at 1 metre, $\mathrm{LP}=$ Light perception, $\mathrm{NLP}=$ No light perception

Table 3

Clinical symptoms of patients with retinitis pigmentosa

\begin{tabular}{ll}
\hline Symptoms* & No. of patients \\
\hline Poor vision & 27 \\
Night blindness & 17 \\
Headaches & 4 \\
Difficulty with hearing & 1 \\
Floaters & 2 \\
Flashes of light & 1 \\
\hline
\end{tabular}

* Many of the patients had more than one symptom

The duration of symptoms varied from two months to as long as thirty years in the older patients, with mean duration of $10.2 \pm 9.7$ years. Two of the patients were siblings (male and female). They were the only ones with retinitis pigmentosa in their family. There was no positive family history in the other patients.

The symptoms at presentation are shown in Table 3. The commonest mode of presentation was poor vision in twenty seven patients (90\%) followed by night blindness in seventeen patients $(56.7 \%)$. Other symptoms were headaches in four patients, flashes of light and floaters in three patients. Fundus examination showed the typical bone corpuscular pigmentary changes and a pale waxy disc in most of the patients.

Only one patient was deaf, but there were no other features of Usher's syndrome.

\section{DISCUSSION}

Retinitis pigmentosa is the most common hereditary chorioretinal dystrophy(6) and is associated with numerous and varied ocular and systemic disorders $(3,6)$. Progressive night vision in the first or second decade of life is the usual mode or presentation(6). It is not surprising that majority of patients (twenty seven) in this study presented with poor vision as visual acuity has been rated to be most strongly related to patients rating of their difficulty in performing daily activities(7). The long duration of the disease in some of the patients (mean $10.2 \pm 9.7$ years) also explains the poor visual acuity as Marmor(8) has shown that visual loss begins at any age in retinitis pigmentosa patients, but generally drops to $6 / 60$ or less within a period of four to ten years. The high number of patients, $(50 \%)$ with visual acuity of less than $3 / 60$ is in sharp contrast to the report by Grover et al.(4) on visual impairment in Americans with retinitis pigmentosa where $80 \%$ of the patients had visual acuity better than $20 / 200(6 / 60)$ or less within a period of four to ten years. The high number of patients, $(50 \%)$ with visual acuity of less than $3 / 60$ is in sharp contrast to the report by Grover et al.(4) on visual acuity impairment in Americans with retinitis pigmentosa where $80 \%$ of the patients had visual acuity better than 20/200 (6/60) and 55\% had visual acuity of 20/40 (6/12) or better.

Pearlman et al.(9) also found that $52 \%$ of his patients had visual acuity better than 20/50.

The high number of patients above 20 years of age in this present study and the long duration of symptoms in them may explain this high rate of poor vision as it has been shown that the proportion of retinitis pigmentosa patients with visual acuity increases with age(8). Marmor(8) observed that $60 \%$ to $90 \%$ of his patients (with either autosomal recessive or autosomal dominant retinitis pigmentosa under the age of 20 years have visual acuity of $6 / 12(20 / 40)$ or better and this percentage decreased to $25 \%$ by age 50 . Thus few patients with retinitis pigmentosa will have visual acuity of $6 / 60(20 / 200)$ or worse before age 20 years, but by age 50 years at least $50 \%$ will be affected to that degree(8). The high number of patients $15(50 \%)$ with visual acuity of less than $3 / 60$ in this present study on Nigerians is sad as these patients are blind and they require rehabilitation. Patients with autosomal dominant retinitis pigmentosa in America were found to have less severe visual acuity impairment compared to those with $\mathrm{X}$-linked recessive disease(4). The genetic subtypes 
were not determined in this present study due to the absence of facilities for routine genetic study. There was no positive family history in the two patients who were siblings or in the other patients but the mode of inheritance in these patients could be X-linked recessive or autosomal recessive and this may then explain the poor vision in this group of patients compared with those in the united states(4) as the mean ages of both groups of patients are similar (41 years in the study by Grover et al.(4) and 36.7 years in the present study). The term 'simplex' denotes that no family history of retinitis pigmentosa could be found in the patient and the Mendelian pattern of inheritance could not be determined $(10,11)$. The term 'multiplex' refers to families where one or more siblings are affected, but there is no family history outside the sibship of retinitis pigmentosa $(5,6,10)$. It is to be assumed that the Mendelian inheritance is autosomal recessive, but other possibilities exist and the term 'multiplex' reflects this variability $(10,11)$. Thus the patients in Benin City, Nigeria can be referred to as having retinitis pigmentosa simplex and the two siblings as having retinitis pigmentosa multiplex.

It is not surprising that $56.7 \%$ of the patients in Benin City presented with night blindness as this is a well known feature of retinitis pigmentosa( $(1,6,10)$. Headache is not a common feature associated with retinitis pigmentosa as only four patients(13.3\%) complained of headache. Patients with retinitis pigmentosa may complain of flashes of light, which may be associated with retinal detachment(10). Only two patients in our study had flashes of light, but there was no retinal detachment.

This study has shown that patients with retinitis pigmentosa in Benin City, Nigeria have clinical presentation similar to that of retinitis pigmentosa patients in developed countries except that the degree of visual impairment is worse and more severe in Nigerians from the long duration of the disease and age of these patients at presentation.

Efforts should be directed at determining the mode of inheritance in these patients as this will help in genetic counseling of the patients. It will also help the doctor to advise the patient about the prognosis and prospects of retaining good vision in the future. Daily intake of oral vitamin A helps in retarding the progression of the disease and the deterioration of vision $(6,12)$ while carbonic anhydrase inhibitors improve the visual function in patients with macula oedema $(6,13)$. The patients can also be advised about the availability of ultraviolet screening lenses and the regular use of antioxidants such as ascorbic acid and beta-carotene, which are believed to be helpful in protecting the patient with retinitis pigmentosa(14). Grid laser photocoagulation has also been shown to improve or stabilise vision(6).
The lack of reports on retinitis pigmentosa in Nigerians may be related to the absence of facilities for electroretinographic and genetic studies. The fact that only thirty patients presented with retinitis pigmentosa at the University of Benin Teaching Hospital during the study period is not a true reflection of its prevalence in the community as this is a hospital based study. Retinitis pigmentosa is a chronic condition and it is likely that the patients who come to the hospital are those with problems such as visual loss, hence the long duration of onset of the disease.

Health education of the public, patients and relatives should be done about the need for early presentation to hospital and rehabilitation of patients with retinitis pigmentosa before the onset of visual loss. The improved visual prognosis with the use of vitamin A therapy and carbonic anhydrase inhibitors should be explained to them.

Availability of facilities for genetic studies in Nigeria will help in genetic counselling and determination of the visual prognosis in these patients. The different studies on genetic abnormalities including the identification of chromosomal loci and genetic mutations in retinitis pigmentosa promise to provide a better understanding of the disease and also help in development of rational treatment that may ultimately lead to disease cure $(5,6)$. Retinal pigment epithelium and photoreceptor transplantation for retinitis pigmentosa promise to be a viable therapeutic alternative $(6,15)$ as improved visual activity has been reported in blind patients with retinitis pigmentosa who were transplanted with neural fetal retina(15).

\section{ACKNOWLEDGEMENTS}

To the Chairman, Medical Advisory Committe, University of Benin Teaching Hospital for permission to publish this manuscript.

\section{REFERENCES}

1. Hruby, K. Retinitis pigmentation. Chibret. J. Ophthalmol. 1983; 1:9-21.

2. Fishman, G.A. Retinitis pigmentosa. genetic percentage. Arch. Ophthalmol. 1978; 96:822-826.

3. Jurklies, B., Zrenner, and E., and Wessing, A. Retinitis pigmentosa-clinical genetic and pathophysiological aspects. Klin-Monatsbl Augenheilkd. 1997; 210:1-18.

4. Grover, S., Fishman, G.A; Alexander, K.R., Anderson, R.J. and Derlacki, D.J. Visual acuity imparment in patients with retinitis pigmentosa. Ophthalmology. 1996; 103:1593-1600.

5. Soest, S.V., Westerveld, A. Dejong P.T.V.M. et al. Retinitis pigmentosa. Defined from a molecular point of view. Current research. Cotler, E. Weinreb, R. (eds). Survey Ophthalmology. 1999; 4:321-334.

6. Noble, K.G., Hereditary chorioretinal dystrophies In: Freeman, W.R. Practical atlas of retical disease and therapy. 2nd edition. Lippincott-Raven Publishers, Philadelphia. pp 1-18. 
7. Szlyk, J.P., Fishman, G.A., Alexander, K.R. Revelins, B.I., Derlacki, D.J., and Anderson, R.J. Relationship between difficulty in performing daily activities and clinical measures of visual function in patients with retinitis pigmentosa. Arch. Ophthalmol. 1997; 115:53-59

8. Marmor, M. F. Visual loss in retinitis pigmentosa. Amer. J. Ophthalmol. 1990; 89:692-698.

9. Pearlman, J. T., Axelrod, R. N., and Tom, A. Frequency of central visual impairment in retinitis pigmentosa. Arch. Ophthalmol. 1977; 95:894.

10. Heckenlively, J. R., Yoser, S. L., and Friedman, L. H., and Oversier, J. J. Clinical findings and common symptoms in retinitis pigmentosa. Amer. J. Ophthalmol. 1988; 105:504-511.

11. Heckenlively, J. R., Boughman, J. A., and Friedmann,
L. H. Pedigree Analysis. In Heckenlively JR (ed.). Retinitis Pigmentosa. JB Lippincott 1987. Philadelphia. pp 19-21.

12. Berson, E. L., Rosner, B., Sandberg, M. A. et al. A randomized trial of vitamin A and vitamin E supplementation for retinitis pigmentosa. Arch. Ophthalmol.1993; 111:761-772.

13. Grove, S., Fishman, G. A., Fiscella, R. G., and Adelman, A. E. Efficacy of dorzolamide hydrochloride in the management of chronic cystoid macula edema in patients with retinitis pigmentosa. Retina. 1997; 17:222-231.

14. Young, R. W. Solar radiation and age related macular degeneration. Surv. Ophthalmol. 1988; 32:252.

15. del-Cerro, M., Lazar, E. S., Loreto, D. Jr. The first decade of continuous progress in retinal transplantation. MicrosRes. Tech. 1997; 36:130-141. 